\title{
Electric Machines \& Their Comparative Study for Wind Energy Conversion Systems (WECSs)
}

\author{
Md. Rejwanur Rashid Mojumdar, Mohammad Sakhawat Hossain Himel, Md. Salman Rahman, and \\ Sheikh Jakir Hossain
}

\begin{abstract}
Wind energy is currently one of the most costeffective energy source to produce electricity among different renewable resources. With significant growth of wind power capacity installed worldwide and rapid development of technologies, various Wind Energy Conversion Systems (WECSs) with different electric machines have been developed during last two decades to maximize the energy capture, to minimize costs, to improve power quality and so on. Within the scope of this review, a comparative study of different WECSs with specific electric machines has been presented describing their concepts, idiosyncrasies, classifications, advantages, disadvantages and current market trends.
\end{abstract}

Index Terms-WECSs, fixed speed concept, variable speed concepts, direct-drive concepts, geared-drive concepts, partialscale converter, full-scale converter.

\section{INTRODUCTION}

Among different renewable energies, wind energy has achieved the fastest growth in the world. The wind power industry has experienced an average growth rate of $27 \%$ per year between 2000 and 2011 [1]. $41 \mathrm{GW}$ of new wind power capacity was added in 2011 which is more than any other renewable technology [2]. The total wind power capacity at the end of 2011 has reached $238 \mathrm{GW}$. It is expected that, this figure will have increased to well over $1260 \mathrm{GW}$ by 2020 , which will be sufficient for $12 \%$ of the world's electricity consumption [3], [4]. This scenario always pushes the global market for wind technology into a more competitive area.

Since 1970s, the modern WECSs have been developing and the rapid development has been seen from 1990s. Various wind turbine concepts have been developed majorly to maximize annual energy capture, minimize costs and improve power quality. These concepts can be classified in various ways. At first, according to size of electrical power output, WECSs can be small (up to $2 \mathrm{~kW}$ ), medium (2-100kW) and large (100kW and up) sized. Small and medium size WECSs are used for remote applications to several residences or local use whereas large WECSs generate power for distribution in central power grids. Due to their greater contribution and importance to the total wind power capacity, large sized WECSs are the focus of this review.

Manuscript received December 18, 2014; revised June 26, 2015

Md. Rejwanur Rashid Mojumdar and Mohammad Sakhawat Hossain Himel are with the Department of Biomedical Physics \& Technology, University of Dhaka, Bangladesh (e-mail: md.rejwanur.rashid.mojumdar@gmail.com, himel2133mcc@gmail.com).

Md. Salman Rahman and Sheikh Jakir Hossain are with Samsung R\&D Institute Bangladesh Ltd., Bangladesh (e-mail: salman2135@gmail.com, jakirjamil@gmail.com).
According to the rotation speed, wind turbine concepts can be of three types - fixed speed, limited variable speed and variable speed. Then based on the rating of power converter, variable speed wind turbines can be classified as a partial scale or a full-scale power electronic converter system. Again, considering the drive train components, the variable speed wind turbine concepts can be classified into multiple-stage geared drive, single-stage geared drive and direct-drive wind turbines [5]. Finally WECSs can be classified according to the types of generator used such as Squirrel Cage Induction Generator (SCIG), Wound Rotor Induction Generator (WRIG), low-speed high-torque synchronous generator, Permanent Magnet Synchronous Generator (PMSG)etc.

In the following sections, the basic configurations and characteristics of different wind generator systems are described with their main advantages and disadvantages. At the end, an overview of market penetration of different concepts and their future potential is discussed.

\section{WECSS' CONCEPTS AND CHARACTERISTICS}

\section{A. Fixed Speed Concept}

This WECS configuration is known as the "Danish concept" because it was developed and widely used in Denmark during the 1980s and 1990s [3], [6]. Fixed-speed WECSs operate at constant speed regardless of the wind speed where the rotor speed is fixed and determined by the grid frequency. These systems have a multiple-stage gearbox and a SCIG directly connected to the grid through a transformer as illustrated in Fig. 1.

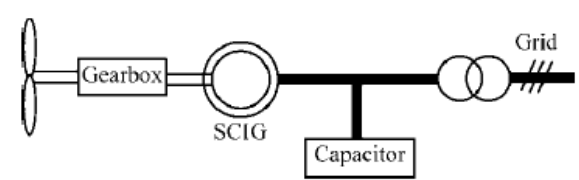

Fig. 1. Scheme of a fixed speed concept with SCIG system [5].

This concept was extended with a capacitor bank for reactive power compensation, since the SCIG always draws reactive power from the grid. A soft-starter was incorporated to achieve smoother grid connection.

To increase the power efficiency, the generators of some fixed-speed WECSs have two winding sets and thus two speeds for speed variation of wind.

\section{1) Advantages}

1) It is mechanically simple, very robust and stable [7].

2) It has low specific mass $(\mathrm{kg} / \mathrm{kW})$ and smaller outer diameter (low number of poles) hence lower cost [8]. 
3) It enables stall-regulated machines to operate at a constant speed so it provides a stable control frequency [5].

\section{2) Disadvantages}

1) Speed control is not possible. Only a pole-changeable SCIG can be used which leads two rotation speeds [8].

2) The turbine speed cannot be adjusted to the wind speed to optimize the aerodynamic efficiency [3], [6], [9]-[12].

3) Wind speed fluctuations are directly translated into electromechanical torque variations which cause high mechanical and fatigue stresses on the system [3], [6], [9]-[12].

4) A three-stage gearbox in the drive train represents a large mass in the nacelle and also a large investment cost [5].

5) Machine's requirement of reactive power cannot be controlled. So this system is incapable to support grid voltage control [8].

6) SCIG gets disconnected from the grid for quite small disturbances. They are incapable of fault-ride through [8].

\section{B. Limited Variable Speed Concept}

This WECS configuration is known as the "Optislip". They are equipped with a WRIG with variable external rotor resistance, controlled by power electronic converter and the pitch control method. Thus, the total (internal plus external) rotor resistance is adjustable to control the slip of the generator and hence the slope of the mechanical characteristic. Obviously, the range of the dynamic speed control is determined by size of the additional resistance [7]. Usually the control range is up to $10 \%$ over the synchronous speed [3], [6], and [10]. But the reactive power compensation and a softstarter are still required for this concept. This Concept is illustrated in Fig. 2.

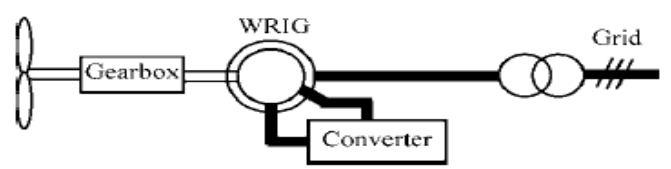

Fig. 2. Scheme of a limited variable speed concept with WRIG system [5].

\section{1) Advantages}

1) Variable speed operation can be achieved.

\section{2) Disadvantages}

1) Reactive power compensation \& soft starter required.

2) Due to gearbox \& converter system, cost increases.

3) The power is dissipated in the external resistor.

\section{Variable Speed Concept with a Partial-Scale Converter}

This configuration is known as the "Doubly-Fed Induction Generator (DFIG)" concept because the stator voltage is applied from the directly connected grid and the rotor voltage is impressed by the partial-scale power converter comprised of two IGBTs. The rotor side converter controls the generator in terms of active and reactive power, while the grid side converter controls the DC-link voltage and ensures operation at a large power factor. The stator outputs power into the grid all the time. The rotor, depending on the operation point, is feeding power into the grid when the slip is negative (oversynchronous operation) and it absorbs power from the grid when the slip is positive (sub-synchronous operation) [7] This Concept is illustrated in Fig. 3.

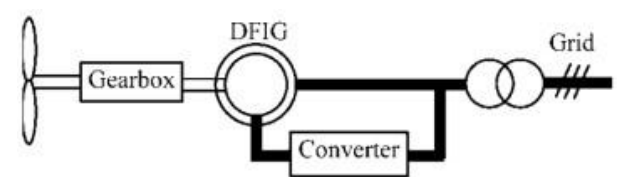

Fig. 3. Scheme of a variable speed concept with DFIG system [5].

\section{1) Advantages}

1) Instead of being dissipated, the rotor energy can be fed into the grid by the power electronic converter [5].

2) Reactive power compensation, voltage support towards the grid and smooth grid connection is performed by the grid- side power converter [5].

3) DFIG supports a wide speed range operation; typically variable speed range is $+30 \%$ around the synchronous speed [3], [6], [9]-[11].

4) The rating of the power electronic converter is only 25$30 \%$ of the generator capacity, which makes this concept attractive from an economic point of view [5].

\section{2) Disadvantages}

1) A gearbox in the drive train is required which shows a reliability negative record and causes higher cost [8].

2) DFIG has brushes which need regular inspection and replacement. They are a potential cause of machine failure and electrical losses [8].

3) Under grid fault conditions, large stator currents result in large rotor currents, so that power electronic converter needs to be protected from destroy [3], [6], [10], [12].

\section{Variable Speed Direct-Drive Concept with Full-Scale Power Converter}

The direct-drive generator rotates at a low speed, because the generator rotor is directly connected on the hub of the turbine rotor. To deliver a certain power, the lower speed makes it necessary to produce a higher torque with a lowspeed high-torque synchronous generator of larger size, multi- pole with a reasonable pitch [5].

Full-scale converter means both the stator and rotor of the generator is connected to the grid through power converter. The amplitude and frequency of the voltage can be fully controlled by the power electronic at the generator side, so that the generator speed is fully controllable over a wide range, even to very low speeds [5].

\section{1) Advantages}

1) By omitting the gearbox, it has the simplified drive train, high overall efficiency, high reliability and availability.

2) The full-scale power converter can perform smooth grid connection over the entire speed range [5].

\section{2) Disadvantages}

1) It has high specific mass $(\mathrm{kg} / \mathrm{kW})$ and large outer diameter (high number of poles) hence higher cost and more weight.

2) It has a higher cost and a higher power loss in the power electronics, since all the generated power has to pass through the power converter [5].

Basically, direct-drive generators used in the market can be classified into two categories: 
- Electrically excited Synchronous generator (EESG)

The EESG is usually built with a wound-rotor synchronous generator and the rotor of that generator carries the field system provided with a DC excitation. This Concept is illustrated in Fig. 4.

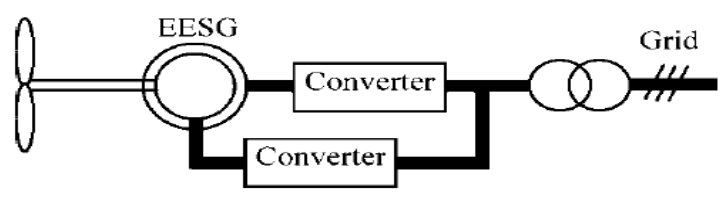

Fig. 4. Scheme of a direct-drive EESG system [5].

\section{3) Advantages}

1) EESG has the opportunities of controlling the flux for a minimized loss in different power ranges, because the excitation current can be controlled by means of the power converter in the rotor side [5].

2) It does not require the use of PMs, which would represent a large fraction of the generator costs.

\section{4) Disadvantages}

1) It is necessary to excite the rotor winding with DC, using slip rings and brushes, or brushless exciter, employing a rotating rectifier and the field losses are inevitable [13], [14].

2) In order to arrange space for excitation windings and pole shoes, it becomes a heavy weight and expensive solution.

- PM Synchronous generator (PMSG)

The PMSG is a good option to be used in WECSs, due to its self-excitation property, which allows operation at high power factor and efficiency. PMSG does not require energy supply for excitation, as it is supplied by the permanent magnets. The stator of a PMSG is wound and the rotor has a permanent magnet pole system. The salient pole of PMSG operates at low speeds, and thus the gearbox can be removed [7]. This Concept is illustrated in Fig. 5.

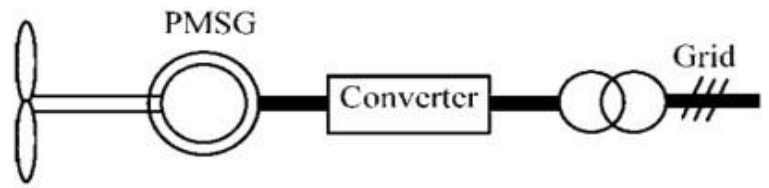

Fig. 5. Scheme of a direct-drive PMSG system [5].

PM machines are not standard off-the-shelf machines and they allow a great deal of flexibility in their geometry, so that various topologies may be used. Primarily, PMSG can be classified based on their flux penetration - radial-flux PM machines, axial-flux PM machines and transversal-flux PM Machines [5].

\section{5) Advantages}

PMSG has following advantages as described in [13], [14]:

1) Higher efficiency and energy yield.

2) No additional power supply for the magnet field excitation.

3) Improvement in the thermal characteristics of the PM machine due to the absence of the field losses.

4) Higher reliability due to the absence of mechanical components such as slip rings.
5) Lighter and therefore higher power to weight ratio.

6) Disadvantages

1) High cost of PM material.

2) Difficulties to handle in manufacture.

3) Demagnetization of PM at high temperature.

\section{E. Other Potential Concepts for WECSs}

Some other types of WECSs are also available in the market, such as variable speed single-stage geared concept with a full-scale power converter and variable speed multiplestage geared concept with a full-scale power converter. In case of variable speed single-stage geared concept, a variable speed pitch control wind turbine is connected to a single-stage planetary gearbox that increases the speed by a factor of roughly 10 to rotate a low-speed permanent-magnet generator. The grid connection scheme of this concept is shown in Fig. 6.

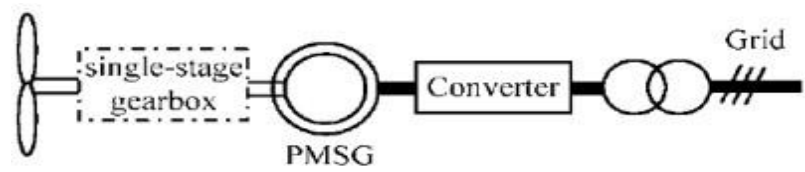

Fig. 6. Scheme of a direct-drive PMSG system [5].

This concept, which was introduced as the Multibrid, has gained the attention because it has the advantages of a higher speed than the direct-drive concept and a lower mechanical component than the multiple-stage gearbox concept [5].

In case of variable speed multiple-stage geared concept with a full-scale power converter, a PMSG system with a multiple gearbox or a multiple-stage geared SCIG system with a full- scale converter is introduced to get some advantages over the "Danish Concept" such as brushless generator with better efficiency, less complex grid-fault ride-through capability, better performance of reactive power compensation etc. But this concept has demerits of using more expensive converter $(100 \%$ of rated power instead of $30 \%$ ). The losses will also be higher as all powers are processed by the power electronic converter. This Concept is illustrated in Fig. 7.

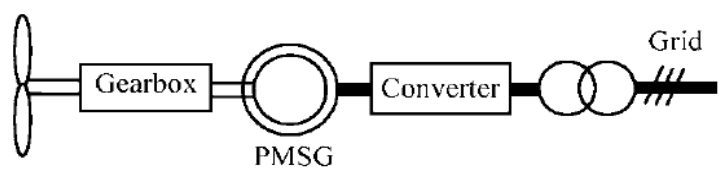

Fig. 7. Scheme of a multiple-stage geared system with a full- scale converter [5].

Many other concepts are found in literature and research, such as linear induction generators [15], switched reluctance generators [16], claw-pole generators [15], brushless DFIGs [15], high temperature superconducting generator [17] etc. Some of these concepts such as brushless DFIGs (BDFIGs) and high temperature superconducting generators (HTS Generators) seem to have promising future. But to discuss about all these concepts is out of scope for this review.

\section{MARKET PENETRATION AND TRENDS OF DIFFERENT WIND TURBINE CONCEPTS}

Table I shows top 10 globally wind turbine manufacturers 
of 2009 and their used generator concepts. According to this table it is clear that the wind market is still dominated by DFIG with a multiple-stage gearbox and the majorly used generator type is still the induction generator. Comparing over 15 years, fixed speed and limited variable speed concepts are almost phased out. Permanent magnet generators and direct drives are getting popular.

Among variable speed concepts, the main advantage of DFIG is that there is only $30 \%$ of the generated power passing through the power converter, so that it may have substantial cost advantages even with low cost power electronics in the future. However, DFIG system has to endure large peak currents during grid faults so that an advanced protection system may be required [5]. This phenomenon may lead towards more popularity of variable speed wind turbine concepts with a full-scale power converter.

Higher overall efficiency, reliability and availability because of omitting the gearbox is the main advantages of direct-drive wind generator systems. Besides, the performance of PMs is improving and the cost of PM is decreasing in recent years. In addition to that, the cost of power electronics is decreasing. Hence, for offshore wind powers, variable speed direct-drive PM machines with a full-scale power converter may become more attractive.

TABLE I: TOP 10 GLOBALLY WIND TURBINE MANUfACTURERS OF 2009, USED GENERATOR CONCEPTS [18]

\begin{tabular}{|c|c|}
\hline Manufacturer & Concept \\
\hline Vestas (Denmark) & $\begin{array}{l}\text { Doubly-Fed Induction Generator (DFIG) } \\
\text { PMSG, multiple gearbox with full converter }\end{array}$ \\
\hline $\begin{array}{l}\text { General Electric } \\
\text { (US) }\end{array}$ & $\begin{array}{l}\text { Doubly-Fed Induction Generator (DFIG) } \\
\text { PMSG, multiple gearbox with full converter } \\
\text { PMSG Direct-Drive with full converter }\end{array}$ \\
\hline Sinovel (China) & Doubly-Fed Induction Generator (DFIG) \\
\hline Enercon (Germany) & EESG Direct-Drive with full converter \\
\hline Goldwind (China) & PMSG Direct-Drive with full converter \\
\hline Gamesa (Spain) & $\begin{array}{l}\text { Doubly-Fed Induction Generator (DFIG) } \\
\text { PMSG multiple gearbox with full converter }\end{array}$ \\
\hline Dongfang (China) & Doubly-Fed Induction Generator (DFIG) \\
\hline Suzlon (India) & IG; Fixed or limited variable speed \\
\hline Siemens (Germany) & $\begin{array}{l}\text { IG; multiple gearbox with full converter } \\
\text { Direct-Drive }\end{array}$ \\
\hline Repower (Germany) & Doubly-Fed Induction Generator (DFIG) \\
\hline
\end{tabular}

\section{Wind TURbine Modeling In STATE OF THE ART PERSPECTIVE}

Wind energy production is gaining increased amount of popularity in both sides of Atlantic day by day. However, there still remain some impediments about the grid integration, production and optimal generation of wind energy using popular models of wind turbine. Though the currently used models have their pros and cons and there remain problems about the voltage drop and frequency matching of the wind turbines. Here, a comparison is made between the popular and widely accepted models of wind turbine.

The variable-speed, pitch-controlled (VSPC) turbines brought a significant improvement in terms of the overall efficiency and cost management of the wind energy production. This technology created a hype of " 5 cent per kilo watt hour" which was widely appreciated at all corners of power systems arena. However, the actual cost was quite more than that. Of its variations, the multiple-stage geared-drive DFIG with a partial-scale power converter is the best considering the fact that only maximum $30 \%$ of the produced power passes through the power-converter. On the other hand, additional safety measures are needed to deal with large amount of peak current during faulty conditions.

The direct-drive concept sounds lucrative in many aspects because it simply eliminates the presence of gearbox at the turbine which significantly increases the system efficiency. This concept is in turn increases the size of the turbine but for the offshore installments that will not be a problem. On the other hand, considering the power generation and generator weight, PM excited generators are quite suitable option for offshore installments. RFPM machines with surface-mounted PM may be more suitable for generation of electricity if we make a comparison between RFPM (radial flux permanent magnet), AFPM (axial flux permanent magnet) and TFPM (transverse flux permanent magnet) generators .Though TFPM can emerge as the popular choice of wind energy production design by some sort of modification and improvement because of ever decreasing cost and ever improving performance of permanent magnets. Furthermore the structure of the TFPM generators are also very conducive to installation of them in different land types. Thus, in future, the solution can be a variable speed generator with full scale power converter and multiple stage gearbox. Moreover, there will be continual improvement and integration of power electronics with power systems to maximize output and making the production system less susceptible to grid faults.

Lots of research have been going on about offshore turbines because it is necessary for the offshore turbines to be extremely robust and less sensitive to disaster or fault because of their location and estimated cost for maintenance. Currently offshore wind power production is the most expensive form considering the installation cost. On the other hand, offshore winds are the strongest in afternoon when people are using the electricity most. As a result, in future we will see considerable changes in the production technology regarding the wind energy production. Floating wind turbines are also being developed which will be popular in very short time and help in the evolution of wind energy production. The cut-in and cut- off speed are also two important criteria which also needs to be considered in the design of turbines.

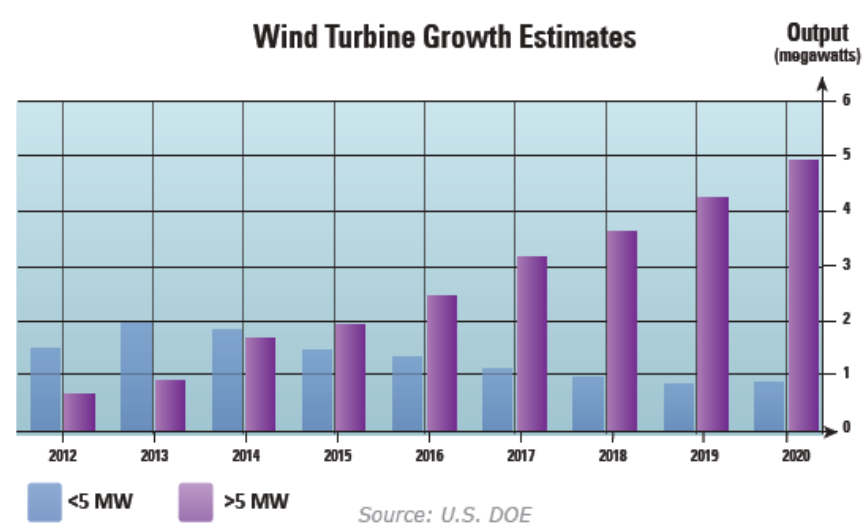

Fig. 8. Wind turbine growth estimates [19].

Superconducting wires are going to play a very important role in the production of wind energy in coming future. This is 
because of the fact that in comparison with same volume of copper wires which is being used conventionally, the superconducting wire has less weight and much higher efficiency. Moreover, considering offshore wind turbines, they are going to be used in a much popular manner as they can reduce the overall weight of the structure and going to increase the production to a great deal. At present, the principal source of wind energy is land based. However, the land based wind turbines are not adequate to meet the large demand of wind energy and the current technology which is being used is not enough for offshore establishments. So, superconducting wires are going to be used in future widely.

In general, wind turbines which are being used in land are going to have much less efficiency than the offshore turbines. This is primarily because of strong currents and because of having very less obstructions. Though wind turbines at offshore are quite expensive in installation, their payback will be much more than their land counterparts.

Superconducting technology is the main way to achieve more than 5 Mega Watt energy from a wind turbine. Current wound rotor and stator generator technology will prove insignificant at these higher levels. In addition, if power generation of more than 10 Kilo watt is to be considered, the prospect of new technology is to be considered [19].

\section{CONCLUSION}

The market of wind power technologies is very active. Though some concepts have already gained much popularity, new concepts are always competing for their share. As wind power penetration to the modern power system is everincreasing, grid connection issues are posing several new challenges to wind turbine design and development. It is certain that, the future success of any wind turbine concept will strongly depend on their ability of complying both market expectations and the requirements of grid utility companies.

\section{REFERENCES}

[1] Global Status Report. (2011). Renewable energy policy network for the 21st century. [Online]. Available: http://germanwatch.org/klima/gsr2011.pdf

[2] Global Wind Report. (2011). Global wind energy council (GWEC). [Online]. Available: http://gwec.net/wp-content/uploads/2012/06/GWEC_Global_Wind_S tatistics_2011.pdf

[3] A. D. Hansen and L. H. Hansen, "Wind turbine concept market penetration over 10 years (1995-2004)," Wind Energy, vol. 10, no. 1, pp. 81-97, 2007.

[4] I. Erlich, W. Winter, and A. Dittrich, "Advanced grid requirements for the integration of wind turbines into the German transmission system," in Proc. IEEE Power Engineering Society General Meeting, June 2006, pp. 18-22.

[5] H. Li and Z. Chen, "Overview of different wind generator systems and their comparisons," IET Renewable Power Generation, vol. 2, pp. 123-138, 2008

[6] L. H. Hansen, L. Helle, F. Blaabjerg et al., "Conceptual survey of generators and power electronics for wind turbines," Riso National Laboratory Technical Report, Riso-R-1205(EN) Roskilde, Denmark, December 2001.

[7] I. Munteanu, A. I. Bratcu, N.-A. Cutululis, E. Ceanga. (2008). Optimal Control of Wind Energy Systems Towards a Global Approach, 1st ed. [Online]. $\quad$ p. $203 . \quad$ Available: http://www.springer.com/978-1-84800-079-7

[8] Y. Shankir, "Review of wind turbines' drive systems and why gearless direct drive," in Proc. RCREEE Wind Energy Building Capacity Program-Stage 2, Rabat, Tangier, March 29-April 2, 2010.
[9] H. Polinder and J. Morren, "Developments in wind turbine generator systems," Electrimacs, Hammamet, Tunisia, 2005.

[10] M. R. Dubois, H. Polinder, and J. A. Ferreira, "Comparison of generator topologies for direct-drive wind turbines," in Proc. Nordic Countries Power and Industrial Electronics Conf. (NORPIE), Aalborg, Denmark, June 2000, pp. 22-26.

[11] O. Carlson, A. Grauers, J. Svensson et al., "A comparison of electrical systems for variable speed operation of wind turbines," in Proc. European wind Energy Conf., 1994, pp. 500-505.

[12] J. Soens, "Impact of wind energy in a future," $\mathrm{PhD}$ dissertation, Wettelijk Depot, UDC 621.548, December 2005.

[13] M. R. Dubois, "Optimized permanent magnet generator topologies for direct-drive wind turbines," $\mathrm{PhD}$ dissertation, Delft University Technology Delft, The Netherlands, 2004.

[14] A. Grauers, "Design of direct-driven permanent-magnet generators for wind turbines," PhD dissertation, Chalmers University of Technology, Goteburg, 1996.

[15] I. Boldea, The Electric Generators Handbook - Variable Speed Generators, Taylor \& Francis, 2006

[16] D. A. Torrey, "Switched reluctance generators and their control," IEEE Transaction on Industrial Electronics, vol. 49, no. 1, pp. 3-14, 2002.

[17] X. H. Li, Y. G. Zhou, L. Han et al., "Design of a high temperature superconducting generator for wind power applications," IEEE Transactions on Applied Superconductivity, June 2011.

[18] W. S. de Oliveira and A. J. Fernandes, "Global wind energy market, industry and economic impacts," Energy and Environment Research, vol. 2, no. 1, 2012.

[19] Suptech. Motors and generators. [Online]. Available: http://www.suptech.com/Motors_and_Generators_Oct_10.pdf

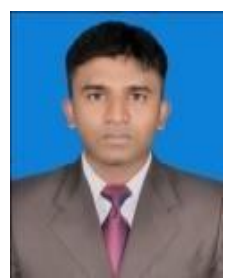

Md. Rejwanur Rashid Mojumdar was born in Dhaka, Bangladesh in 1986. He received his B.Sc. degree in electrical and electronic engineering from Islamic University of Technology (IUT), Bangladesh in November 2008. Since April 2009 to April 2011, he had been working as a site engineer at NLDC (National Load Dispatch Centre) Project of AREVA T\&D Bangladesh. Then he worked as an energy auditor in ESIP (Energy Saving Initiative Project) with cooperation of GIZ GmbH. Besides, he has pursued his masters from Erasmus Mundus masters in sustainable transportation and electrical power systems.

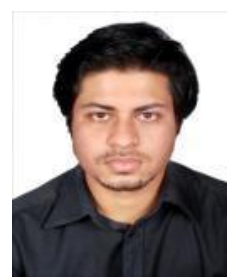

Mohammad Sakhawat Hossain Himel was born on December 20, 1990 at Dhaka. He completed his bachelor of science degree in physics from University of Dhaka, Bangladesh in 2014. He is currently a student of master of science in the Department of Biomedical Physics \& Technology (Medical physics), University of Dhaka. His research interests include space physics, nerve conduction, evoked responses, biophysics. radiological physics statistical mechanics, renewable, nuclear and sustainable energies.

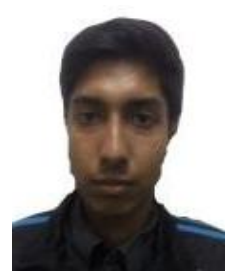

Md. Salman Rahman was born on January 15, 1990 at Mymensingh. He completed his bachelor of science degree in electrical and electronic engineering from Islamic University of Technology (IUT). $\mathrm{He}$ is currently working as a software engineer in Samsung R\&D Institute Bangladesh Ltd. (SRBD) which is an ORC (overseas R\&D Center of Samsung Electronics and located in Dhaka, Bangladesh. His research interests include embedded system, parallel programming biomedical imaging and renewable energy.

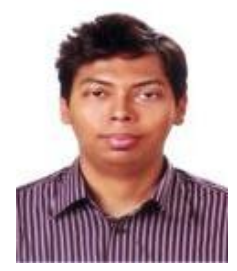

Sheikh Jakir Hossain was born in Bangladesh in 1990. He obtained the B.Sc. degree in electrical and electronic engineering from Bangladesh University of Engineering and Technology (BUET), Dhaka, Bangladesh in 2013. From 2013 he has been working as a software engineer in Samsung $R \& D$ Institute Bangladesh which is an overseas R\&D center of Samsung electronics. His main research interests are power system analysis, distributed generations, smart grids, integration of renewable energies to micro-grids and wider area protection of power systems. 

Natural Gas 
